\title{
Effect of $\beta$ blockade on the neurohumoral and cardiopulmonary response to dynamic exercise in cardiac transplant recipients
}

Sudhir S Kushwaha, Nicholas R Banner, Naina Patel, Andrew Cox, Helen Patton, Magdi H Yacoub

\begin{abstract}
Objective-To determine the effects of a small dose of $\beta$ blocker on neurohumoral and cardiopulmonary responses after cardiac transplantation.

Background-Cardiac transplant recipients have a reduced exercise capacity and abnormal cardiovascular responses to exercise. The sympathoadrenal response to exercise has been shown to be abnormal with high venous noradrenaline. The effect of $\beta$ blockade on these neurohumoral mechanisms has not been defined. Methods-10 non-rejecting cardiac transplant recipients were studied. Patients carried out graded exercise to a symptom limited maximum. Blood samples were taken during exercise. Concentrations of noradrenaline, adrenaline, and atrial natriuretic peptide and plasma renin activity were measured. The next day, the exercise and sampling procedure were repeated after an oral dose of propranolol $(40 \mathrm{mg})$.
\end{abstract}

Results-Patients tolerated exercise poorly after $\beta$ blockade, which was reflected in the maximum workload reached. Heart rate and blood pressure were significantly higher at rest and during exercise before $\beta$ blockade. Although there was no significant difference when resting, mean (SEM) noradrenaline concentrations during peak exercise were higher after $\beta$ blockade (16.2 (2) $v 23.6$ $(2 \cdot 9) \mathrm{nmol} / \mathrm{l}, \mathrm{p}=0 \cdot 001)$. Adrenaline concentrations at peak exercise were also greater after $\beta$ blockade $(0.89(0.31) v 1.18$ $(0.38)$ nmol/1, $p=0.055)$. Atrial natriuretic peptide concentrations tended to be higher after $\beta$ blockade $(118.75(50 \cdot 2) v$ $169 \cdot 79(39 \cdot 3) \mathrm{pmol} / \mathrm{l}, \mathrm{p}=0 \cdot 36)$. There was no significant change in plasma renin activity.

Conclusions-A small oral dose of a competitive $\beta$ blocker such as propranolol has an adverse effect on exercise tolerance and cardiovascular response to exercise in cardiac transplant recipients. There are also increased concentrations of circulating noradrenaline and therefore, sympathetic activity during exercise. $\beta$ blockers should be used with caution in cardiac transplant recipients.

(Br Heart f 1994;71:431-436)
Cardiac transplantation results in denervation of the heart which usually persists indefinitely in human orthotopic cardiac transplants ${ }^{1}$ despite the fact that there have been some recent reports of partial reinnervation..$^{2-4}$ Cardiac transplant recipients have been shown to have a reduced exercise capacity and an abnormal cardiovascular response to dynamic exercise. ${ }^{5}$ Also, the sympathoadrenal response to exercise has been shown to be abnormal with high venous noradrenaline concentrations during dynamic exercise. ${ }^{6}$ This may be a consequence of the dependence of the transplanted heart on circulating catecholamines to produce a heart rate and cardiac output response to exercise.

Cyclosporin is currently the most important immunosuppressive agent used after heart transplantation. ${ }^{8}$ One of the major side effects of this drug is hypertension, which affects a significant number of patients, ${ }^{9}$ and may partially be due to increased sympathetic neural activity caused by cyclosporin. ${ }^{10} \beta$ blockers may potentially be used as a treatment for hypertension in cardiac transplant recipients. ${ }^{11}$ The effect of $\beta$ blockers on the cardiopulmonary response to exercise in heart transplant recipients, other neurohumoral mechanisms, and catecholamine concentrations, has not been adequately defined although the response of heart rate to exercise after $\beta$ blockade is diminished. ${ }^{12}$

The aim of this study was to investigate the effect of a small oral dose of $\beta$ blocker on exercise capacity together with cardiopulmonary and neuroendocrine response during and after dynamic exercise in healthy cardiac transplant recipients with good left ventricular function.

\section{Patients and methods}

Ten cardiac transplant recipients were investigated six to 25 months (mean 8.8) after cardiac transplantation. The mean (range) age of the patients was 43.9 (28 to 64 ) years and all were men. All patients were clinically well at the time of the study with no evidence of cardiac rejection on endomyocardial biopsy. Treatment was by standard immunosuppression with cyclosporin (dose adjusted to maintain a whole blood concentration of $150-250 \mathrm{ng} / \mathrm{ml})$ and azathioprine $(2 \mathrm{mg} / \mathrm{kg})$. The patients were on no other treatment and none were receiving steroids. 
The study protocol was approved by the District Ethics Committee and informed written consent was obtained from all subjects.

\section{EXERCISE STUDIES}

All patients exercised in a preprandial state having fasted for at least three hours. The study was carried out over two consecutive days. On the first day, the exercise procedure was carried out and blood samples were taken for measurement of catecholamine concentrations. The next day, the exercise procedure was repeated after the patient had taken 40 $\mathrm{mg}$ of the $\beta$ blocker propranolol three hours before the procedure. The repeat exercise test was carried out at the same time as that on the previous day.

An indwelling intravenous cannula was inserted into a forearm vein for subsequent blood sampling and kept patent by intermittent flushing with heparinised saline. After an interval of 10 minutes the subject was seated on an electronically braked ergometer (Corval Lode, Groningen, Netherlands). Heart rate and electrocardiographic recordings were taken with a computer assisted cardiograph (Marquette MAC II, Marquette, Manchester). Heart rate and a three lead rhythm strip were recorded at one minute intervals, and 12 lead electrocardiograms were recorded every three minutes.

Blood pressure was measured every three minutes during exercise with a standard mercury syphgmanometer with the subject's arm supported at chest level. The subjects breathed room air through a three way valve box (Hans Rudolph, Kansas City, USA). The expired air was analysed with a Spectramed 9000 computer driven gas analysis system (Cardiokinetics, Salford) that provided minute averaged results for ventilation and oxygen uptake.

Upright exercise was performed on a cycle ergometer. The protocol consisted of four minutes seated at rest to allow heart rate and ventilation to stabilise, then a warm up period of three minutes cycling at $60 \mathrm{rev} / \mathrm{min}$ against a workload of $10 \mathrm{w}$. The workload was then increased in $10 \mathrm{w}$ increments at one minute intervals to symptom limited maximum exercise. Only the results of the last minute at rest and the last minute of the warm up phase were included in the analysis of the exercise data.

Blood samples $(10 \mathrm{ml})$ were taken from the indwelling venous cannula just before the start of the exercise, at the end of the warm up period, and at alternate minutes during exercise (workloads of $30 \mathrm{w}, 50 \mathrm{w}$, etc). The samples were taken into chilled tubes containing lithium heparin and immediately separated by centrifugation at $370 \mathrm{~g}$ for 10 minutes at $4^{\circ} \mathrm{C}$. The separated plasma was frozen in liquid nitrogen until subsequent analysis.

Once the subject reached symptom limited maximum exercise, the external workload was removed from the cycle ergometer. The subject was instructed to continue cycling at 60 $\mathrm{rev} / \mathrm{min}$ for one minute and then stop. During the recovery period heart rate was measured at one minute intervals and blood samples were taken one, three, and six minutes after exercise.

\section{CATECHOLAMINE AND HORMONE ASSAYS}

Noradrenaline and adrenaline concentrations were measured by high performance liquid chromatography with electrochemical detection as previously described. ${ }^{6}$ Briefly, plasma samples were extracted by adsorption on to alumina, and catecholamines were back extracted with acetic acid. 3, 4Dihydroxybenzylamine was used as an internal standard. Chromatography was performed with a $25 \mathrm{~cm}, 5 \mu \mathrm{m}$ Ultrasphere ODS analytical column (Beckmann-RIIC, High Wycombe) with a reverse phase ion pair system and an electrochemical detector (Coulochem model 5100A, ESA, Bedford, Mass). The detection limit for both catecholamines in plasma was $0.02 \mathrm{nmol} / 1$.

Atrial natriuretic peptide was measured by radioimmunoassay as previously described. ${ }^{13}$ Plasma was extracted with SepPak columns (Waters Associates, Boston, Mass), reconstituted in phosphate buffer, and assayed with rabbit antiserum to a human atrial natriuretic peptide (Peninsula Laboratories, Merseyside), ${ }^{125}$ I labelled atrial natriuretic peptide (Amersham International, Amersham), and synthetic atriopeptin III standard (Peninsula Laboratories). The detection limit for atrial natriuretic peptide in plasma was $2.0 \mathrm{pmol} / 1$.

Plasma renin activity was measured by radioimmunoassay of angiotensin I generated by incubation of $1 \mathrm{ml}$ plasma samples for two hours at $37^{\circ} \mathrm{C}$ and $\mathrm{pH} 6$ in the presence of angiotensin converting enzyme inhibitors. ${ }^{14}$ The assay used angiotensin I standard (Peninsula Laboratories), ${ }^{125}$ I labelled angiotensin I (Amersham International), and specific antiserum.

\section{STATISTICAL ANALYSIS}

The results are given as mean (SEM). The catecholamine concentrations at various levels of exercise measured before and after $\beta$ blockade were compared by analysis of variance and where appropriate, the Student's $t$ test for matched samples. The level of significance was taken as $\mathrm{p}<0.05$.

\section{Results}

SYMPTOMS

The $40 \mathrm{mg}$ dose of propranolol used in this study was not well tolerated. All patients reported a greater degree of breathlessness and leg muscle weakness after $\beta$ blockade during the exercise procedure as well as a general lack of energy shortly after taking the drug.

\section{REST AND MAXIMUM WORKLOAD}

At rest all subjects were in sinus rhythm and the electrocardiograms were normal. Each patient exercised to his symptom limited maximum. No adverse reactions or arrhythmias occurred. The limiting symptoms were either leg muscle fatigue (seven patients) or breathlessness associated with general fatigue (three 
Heart rate response, noradrenaline and adrenaline concentrations, and peak oxygen uptake before and after $\beta$ blockade

\begin{tabular}{|c|c|c|c|c|c|c|c|c|c|c|}
\hline \multirow{2}{*}{$\begin{array}{l}\text { Exercise } \\
\text { capacity } \\
\text { (w) }\end{array}$} & \multicolumn{2}{|c|}{$\begin{array}{l}\text { Heart rate response } \\
\text { (beats } / \mathrm{min} \text { ) }\end{array}$} & \multicolumn{2}{|c|}{$\begin{array}{l}\text { Systolic blood } \\
\text { pressure response }(\mathrm{mm} \mathrm{Hg})\end{array}$} & \multicolumn{2}{|c|}{$\begin{array}{l}\text { Noradrenaline } \\
\text { concentration } \\
\text { (nmolll) }\end{array}$} & \multicolumn{2}{|c|}{$\begin{array}{l}\text { Adrenaline } \\
\text { concentration } \\
\text { (nmolll) }\end{array}$} & \multicolumn{2}{|l|}{$\begin{array}{l}\text { Oxygen uptake } \\
\text { (ml/min) }\end{array}$} \\
\hline & Before & After & Before & After & Before & After & Before & After & Before & After \\
\hline Rest & $108 \cdot 6(4 \cdot 5)$ & $80 \cdot 8(3 \cdot 0)$ & $130(4 \cdot 9)$ & $121(4 \cdot 0)$ & $4.3(0.5)$ & $4.5(0.6)$ & $0.2(0.06)$ & $0.2(0.05)$ & $294.7(16 \cdot 8)$ & $290 \cdot 6(15 \cdot 5)$ \\
\hline 10 & $112.0(4 \cdot 8)$ & $89 \cdot 0(4 \cdot 1)$ & $137(5 \cdot 3)$ & $126(3.8)$ & $5.0(0 \cdot 7)$ & $5 \cdot 0(0.7)$ & $0.2(0.04)$ & $0.2(0.05)$ & $605 \cdot 5(26 \cdot 5)$ & $606 \cdot 4(23.8)$ \\
\hline 30 & $113.6(4 \cdot 7)$ & $91 \cdot 7(4 \cdot 2)$ & $148(4 \cdot 2)$ & $130(2 \cdot 9)$ & $5 \cdot 1(0.5)$ & $7 \cdot 2(0 \cdot 8)$ & $0.2(0.03)$ & $0.2(0.03)$ & $678.7(28.5)$ & $674 \cdot 8(26 \cdot 8)$ \\
\hline 50 & $119.2(5.4)$ & $96 \cdot 2(4 \cdot 7)$ & - & - & $5.6(0.6)$ & $9 \cdot 0(1.4)$ & $0.2(0.04)$ & $0.3(0.04)$ & $810.3(33.9)$ & $782.9(34.2)$ \\
\hline 70 & $126 \cdot 6(6 \cdot 0)$ & $101 \cdot 8(5 \cdot 3)$ & $152(6 \cdot 2)$ & $140(3 \cdot 7)$ & $7 \cdot 6(0.8)$ & $11 \cdot 7(1 \cdot 5)$ & $0.3(0.05)$ & $0.3(0.05)$ & $977.0(31 \cdot 3)$ & $917 \cdot 4(33 \cdot 2)$ \\
\hline 90 & $136 \cdot 2(6 \cdot 7)$ & $109 \cdot 1(6 \cdot 7)$ & - & - & $10 \cdot 3(1 \cdot 0)$ & $18 \cdot 1(2 \cdot 2)$ & $0.4(0.07)$ & $0.5(0.1)$ & $1156.4(35.0)$ & $1129 \cdot 0(31 \cdot 7)$ \\
\hline 110 & $144.0(8 \cdot 1)$ & $120.0(18)$ & $174(7 \cdot 6)$ & $144(3.9)$ & $15.3(1.5)$ & $25 \cdot 8(4 \cdot 0)$ & $0.7(0.2)$ & $1.6(0.7)$ & $1263.2(39.7)$ & $1182.3(19.5)$ \\
\hline $1 \mathrm{R}$ & $138 \cdot 2(5 \cdot 5)$ & $100 \cdot 9(4.8)$ & - & - & $14.5(1.9)$ & $18 \cdot 1(2 \cdot 2)$ & $0.7(0.2)$ & $1.0(0.3)$ & - & - \\
\hline $3 \mathbf{R}$ & $130 \cdot 1(5 \cdot 6)$ & $93 \cdot 1(4 \cdot 0)$ & - & - & $10 \cdot 1(1 \cdot 4)$ & $11 \cdot 2(1 \cdot 5)$ & $0.4(0.07)$ & $0.5(0.08)$ & - & - \\
\hline $6 \mathrm{R}$ & $123.8(5 \cdot 1)$ & $87.9(3.7)$ & - & - & $7 \cdot 1(1 \cdot 3)$ & $6.4(0.9)$ & $0.3(0.04)$ & $0.3(0.05)$ & - & - \\
\hline
\end{tabular}

$\mathrm{R}$, recovery time (min).

patients) and were the same for each patient before and after $\beta$ blockade. The maximum workload reached before $\beta$ blockade $(98(4 \cdot 2)$ W) was higher than after $\beta$ blockade (89 (3.8) W), $p=0.029$. This was reflected by a lower peak oxygen uptake after $\beta$ blockade $(1208 \cdot 3$ $(55.9) \mathrm{ml} / \mathrm{min}$ before and $1068.7(55 \cdot 2)$ $\mathrm{ml} / \mathrm{min}$ after, $\mathrm{p}=0.005$ ).

\section{HAEMODYNAMIC RESPONSE}

All subjects remained in sinus rhythm and their electrocardiograms remained within normal limits. Resting heart rates were significantly higher before than after $\beta$ blockade $(108.6(4.45) v 80.8$ (3), $\mathrm{p}<0.0001)$ and rose gradually throughout exercise. Peak heart rates reached during exercise or recovery were $141.9(6.4)$ before and 108.4 (6.3) after $\beta$ blockade ( $<<0.0001$, table, fig 1$)$.

Resting systolic blood pressure was higher before compared with after $\beta$ blockade (130 (4.9) v $120.5(4.0) \mathrm{mm} \mathrm{Hg}, \mathrm{p}=0.02)$. Blood pressure rose to a peak of $170 \cdot 5(7 \cdot 6) \mathrm{mm} \mathrm{Hg}$ before and $144.5(3.3) \mathrm{mm} \mathrm{Hg}$ after $\beta$ blockade $(\mathrm{p}=0.001$, table) .

\section{CATECHOLAMINE CONCENTRATIONS}

There was no significant difference in resting noradrenaline concentrations $(4.3(0.5)$ v 4.5 $(0 \cdot 6) \mathrm{nmol} / \mathrm{l}$, NS) before and after $\beta$ blockade. Noradrenaline rose with increasing levels of exercise both before and after $\beta$ blockade. Peak noradrenaline concentration was $16 \cdot 2$ (2) $\mathrm{nmol} / \mathrm{l}$ before and $23.6(2.9) \mathrm{nmol} / \mathrm{l}$ after $\beta$ blockade $(p=0.001)$. At six minutes recovery the noradrenaline concentration was $7 \cdot 1(1 \cdot 3)$

Figure 1 Heart rate response before and after $\beta$ blockade in 10 cardiac transplant recipients undergoing graded exercise then recovery.

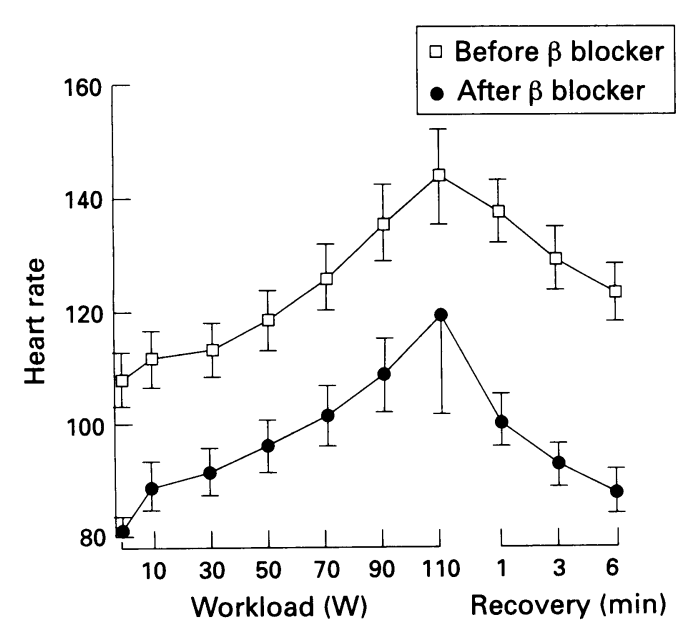

$\mathrm{nmol} / 1$ before $\beta$ blockade and $6 \cdot 4(0.92)$ after $\beta$ blockade, NS (table, fig 2).

There was no significant difference in resting adrenaline concentrations $(0.25(0.06) v 0.19$ $(0.05) \mathrm{nmol} / \mathrm{l}, \mathrm{NS})$ before and after $\beta$ blockade. Mean adrenaline concentrations both before and after $\beta$ blockade showed little tendency to rise before the $90 \mathrm{~W}$ level of exercise. There was no significant difference over most levels of exercise between adrenaline concentrations before and after exercise. The peak adrenaline concentration after $\beta$ blockade was greater than that before $\beta$ blockade and this approached significance $(1.18(0.38) \mathrm{nmol} / 1 \mathrm{v}$ $0.89(0.31) \mathrm{nmol} / \mathrm{l}, \mathrm{p}=0.055$, table $)$.

\section{ATRIAL NATRIURETIC PEPTIDE}

CONCENTRATIONS

Plasma atrial natriuretic peptide showed little tendency to rise before $\beta$ blockade except at the highest level of exercise (NS). Atrial natriuretic peptide concentrations were not significantly different after $\beta$ blockade at any level of exercise. Atrial natriuretic peptide concentrations tended to be higher after $\beta$ blockade although this difference did not reach significance $(118.75(50.2) \mathrm{pmol} / \mathrm{l} v 169.79(39.3)$ $\mathrm{pmol} / \mathrm{l}, \mathrm{p}=0 \cdot 36)$.

\section{PLASMA RENIN ACTIVITY}

There was no significant change in plasma renin activity with progressive increase in exercise either before or after $\beta$ blockade. Peak plasma renin activity was $3087 \cdot 36$ $(545.4) \mathrm{pmol} / 1$ before and $2614.82(503.7)$ $\mathrm{pmol} / 1$ after $\beta$ blockade $(\mathrm{p}=0 \cdot 16)$. In some

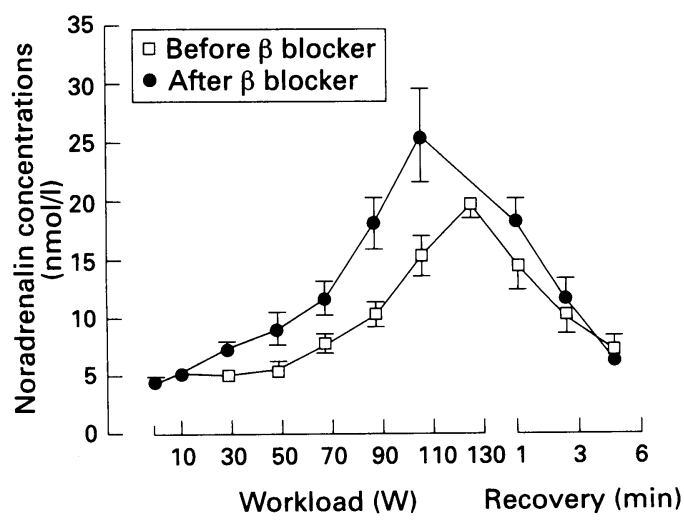

Figure 2 Noradrenaline concentrations before and after $\beta$ blockade in 10 cardiac transplant recipients undergoing graded exercise then recovery. 
individual cases plasma renin was higher at rest before exercise and fell with progressive exercise.

\section{Discussion}

This study has shown that $\beta$ blockade affects several clinical and physiological variables in response to exercise in cardiac transplant recipients. Exercise capacity and the maximum heart rate response to exercise is lower in cardiac transplant recipients than in normal controls. ${ }^{6}$ Our study has shown that both the exercise capacity and the heart rate response is further diminished by a small oral dose of a competitive non-selective $\beta$ blocker such as propranolol.

\section{EFFECT OF $\beta$ BLOCKADE ON THE \\ TRANSPLANTED HEART}

Myocardial $\beta$ adrenoceptors seem to become more effective after cardiac transplantation or denervation as suggested by an increased sensitivity to adrenergic agonists ${ }^{1516}$ as well as from studies of receptor density in biopsy specimens. ${ }^{1718}$ This supersensitivity may be presynaptic in origin. ${ }^{1920}$ Therefore the sensitivity to endogenous catecholamines such as noradrenaline may be greater because of loss of uptake by the postganglionic sympathetic neurones in the denervated heart. This does not influence the effect of isoprenaline on the $\beta$ receptor because it is not a substrate for the uptake process. ${ }^{1621}$

In normal subjects, propranolol competitively blocks $\beta$ adrenergic receptors and decreases many of the measurable indices of myocardial performance such as heart rate, cardiac output, and external left ventricular work..$^{22} \beta$ Blockade with propranolol has been shown to cause increases in concentrations of both adrenaline and noradrenaline in response to acute exercise in normal healthy male subjects. ${ }^{23}{ }^{24}$ Benedict et al have shown that although propranolol caused an increase in resting plasma noradrenaline, it had no effect on the concentration at maximal exercise when compared with the rise induced by exercise itself. ${ }^{25}$

The higher resting noradrenaline concentrations in cardiac transplant recipients compared with normal controls may help to compensate for the effects of denervation on cardiac performance. ${ }^{6}$ Competitive $\beta$ blockade would be expected to interfere with these catecholamine dependent mechanisms of exercise response and limit cardiac output and exercise capacity. Our study has shown that $\beta$ blockade significantly attenuates the heart rate response to exercise in transplant recipients and results in a further increase in circulating catecholamines suggesting that they are necessary to maintain the heart rate and cardiac output in these patients.

\section{EXERCISE RESPONSE}

The cardiac output response in cardiac transplant recipients is initially dependent on increased venous return and a Frank-Starling effect to maintain cardiac output during the early stages of exercise. ${ }^{26}$ In the later stages of exercise, circulating catecholamines increase heart rate and contractility and concentrations of circulating catecholamines are increased during exercise in transplant recipients. ${ }^{626}$ Cardiac denervation in a canine model has been shown to alter the response to dynamic exercise with the heart rate response being reduced and delayed. ${ }^{27}$ Donald and coworkers showed in a study on racing greyhounds with total cardiac denervation, that the achievement of maximal exercise is dependent on circulating concentrations of catecholamines. ${ }^{28}$ After adrenergic $\beta$ blockade with propranolol, not only was the performance of these dogs reduced from normal, but they finished the exercise in a collapsed state. In contrast, the dogs without chronic denervation reached maximal exercise with only a slight decrease in maximal heart rate and a slight increase in racing time after $\beta$ blockade. Versteeg et al also showed in a similar study that after $\beta$ blockade, only two out of seven dogs with denervated hearts were prepared to run at a limited number of speeds. ${ }^{29}$ The findings of our study are also consistent with the findings of Bexton et al who found that heart rate and exercise capacity in cardiac transplant recipients was reduced by intravenous $\beta$ blockade $(0.2 \mathrm{mg} / \mathrm{kg}) .{ }^{12}$ Our group has previously studied the influence of $\beta$ blockade on exercise capacity and heart rate response after cardiac transplantation ${ }^{30}$ and similarly showed a decreased exercise duration and a reduction in the increase of systolic blood pressure. The patients in that study received $0.1 \mathrm{mg} / \mathrm{kg}$ of intravenous propranolol and did not develop symptoms of extreme exhaustion. ${ }^{30}$ In contrast, the patients in the study of Bexton et al received $0.2 \mathrm{mg} / \mathrm{kg}$ of intravenous propranolol and the higher dose of propranolol may explain why the patients were symptomatic. ${ }^{12}$ We did not measure propranolol concentrations but it is likely that the blood concentrations of propranolol reached in our study are comparable with the study by Bexton et al and may explain the similarity in the symptoms in both groups of patients. ${ }^{12}$

\section{CATECHOLAMINE RESPONSE}

Plasma noradrenaline has been used as an indicator of sympathetic neural activity ${ }^{31}$ and concentrations are known to be high in myocardial infarction and congestive heart failure. ${ }^{32}$ Also, cardiac failure is associated with an increased noradrenaline response during exercise. ${ }^{33}$ These effects of heart failure can be partially reversed by treatment with cardiac transplantation. ${ }^{34}$ Circulating noradrenaline concentrations are increased during dynamic exercise in cardiac transplant recipients compared with normal controls. ${ }^{6}$ This may be due to cardiac denervation and an altered cardiac response during dynamic exercise. ${ }^{6}$ Cyclosporin treatment may also play a part. ${ }^{10}$ In our study, $\beta$ blockade increased noradrenaline concentrations even further. Heart rate, blood pressure, and presumably cardiac output were lower after $\beta$ blockade. A possible explanation for the increased 
noradrenaline concentrations may be activation of the arterial baroreceptor reflex after $\beta$ blockade with a consequent increase in activity of the sympathetic nervous system. As $\beta$ blockade is competitive, the higher circulating noradrenaline concentrations may have partly offset the effect of propranolol on the cardiac response to exercise. ${ }^{25}$

\section{ATRIAL NATRIURETIC PEPTIDE RESPONSE}

Atrial natriuretic peptide is released from the atria in response to atrial stretch and seems to play a part in the regulation of blood pressure and salt and water balance. Atrial natriuretic peptide concentrations are increased in heart failure and correlate with the pressures of the left and right atrial..$^{35}$ Atrial natriuretic peptide concentrations decrease after cardiac transplantation, with the resulting improvement in cardiac function and reduction in atrial pressures. ${ }^{36}$ They remain higher than those found in normal subjects matched for age, sex, and blood pressure. ${ }^{37}$ Although atrial natriuretic peptide concentrations increase with dynamic exercise in cardiac transplant recipients, ${ }^{38}$ our study suggests that factors other than a change in heart rate are of importance in the regulation of plasma atrial natriuretic peptide. $\beta$ blockade might be expected to make cardiac transplant recipients more dependent on the Frank-Starling mechanism to increase cardiac output during exercise resulting in increased atrial pressure and secretion of atrial natriuretic peptide. Although atrial natriuretic peptide concentrations tended to be higher, the difference did not reach significance. This may be because any increase may have been affected by the decrease in heart rate after $\beta$ blockade. ${ }^{38}$

\section{RENIN RESPONSE}

Sympathetic stimulation produced by infusion of isoprenaline and during change in posture caused no increase in plasma renin activity in cardiac transplant recipients compared with normal controls in whom there was a higher resting plasma renin activity and a progressive increase with isoprenaline infusion. ${ }^{39}$ The results of our study also showed no significant change in plasma renin activity with progressive exercise before and after $\beta$ blockade. The mechanism may be a cyclosporin mediated effect on the kidney ${ }^{39}$ although other workers have suggested that cyclosporin does not cause major abnormalities of the renin angiotensin aldosterone system. ${ }^{40}$

In conclusion, a small oral dose of a competitive $\beta$ blocker such as propranolol had a definite adverse effect on the exercise tolerance and cardiovascular response to dynamic exercise in cardiac transplant recipients. Also, the drug exaggerated the increased concentrations of circulating noradrenaline and by implication the sympathetic activity during dynamic exercise. Adrenaline, atrial natriuretic peptide and renin concentrations were not affected. These findings suggest that although $\beta$ blockers have been proposed as a treatment for hypertension after cardiac trans- plantation, they should be used with caution in such recipients. It is hoped that the data presented will help in the management of cardiac transplant recipients and provide insights into the physiological mechanisms implicated.

1 Horak A. Physiology and pharmacology of the transplanted heart. In: Cooper DKC, Lanza R, eds. Hear transplantation. Lancaster: MTP Press, 1984:147-56.

2 Stark RP, McGinn AL, Wilson R. Chest pain in cardiac transplant recipients. Evidence of sensory reinnervation after cardiac transplantation. $N$ Engl $\mathcal{F}$ Med 1991;324: 1791-4.

3 Wilson RF, Christensen BV, Olivari MT, Simon A, White $\mathrm{CW}$, Laxson D. Evidence for structural sympathetic reinnervation after orthotopic cardiac transplantation in humans. Circulation 1991;83:1210-20.

4 Mitchell AG, Yacoub M. Efferent autonomic reinnervation after heterotopic cardiac transplantation in humans [abstract]. Br Heart $\mathcal{F}$ 1987;57:87.

5 Kavanagh T, Yacoub MH, Mertens DJ, Kennedy J, Campbell RB, Sawyer P. Cardiorespiratory responses to exercise training after orthotopic cardiac transplantation. Circulation 1988;77:162-71.

6 Banner NR, Patel N, Cox AP, Patton HE, Lachno DR, Yacoub $M$. Altered sympathoadrenal response to dynamic exercise in cardiac transplant recipients. Cardiovasc Res 1989;23:965-72.

7 Banner NR, Yacoub M. Physiology of the orthotopic cardiac transplant recipient. Sem Thorac Cardiovasc Surg diac transplant

8 Schroeder JS, Hunt S. Cardiac Transplantation: where are we? N Engl f Med 1986;315:961-3.

9 Bennett WM, Porter G. Cyclosporine-associated hypertension. Am $\mathcal{F}$ Med 1988;85:131-3.

10 Scherrer U, Vissing SF, Morgan BJ, et al. Cyclosporineinduced sympathetic activation and hypertension after heart transplantation. $N$ Engl $\mathcal{F}$ Med 1990;323:693-9.

11 Yusuf S, Theodoropoulos S, Dhalla N, Mathias C, Yacoub $M$. Effect of beta blockade on dynamic exercise in human heart transplant recipients. Heart Transplantation 1985;4:312-4

12 Bexton RS, Milne JR, Cory-Pearce R, English TAH Camm A. Effect of beta blockade on exercise response after cardiac transplantation. Br Heart $\mathcal{1} 1983 ; 49: 584-8$.

13 Walsh KP, Williams TDM, Canepa-Anson R, Pitts E Lightman SL, Sutton R. Effects of endogenous atrial natriuretic peptide released by rapid atrial pacing in natriuretic peptide released by rapid
dogs. Am $\mathcal{F}$ Physiol 1987;253:R599-604.

14 Boyd GW, Peart W. Angiotensin immunoassay. In: Page IH, Bumpus F, ed. Angiotensin. Berlin: Springer-Verlag, IH, Bumpus

15 Yusuf S, Theodoropoulos S, Mathias CJ, et al. Increased sensitivity of the denervated transplanted human hear to isoprenaline both before and after beta-adrenergic blockade. Circulation 1987;75:696-704

16 Vatner DE, Lavallee M, Amano J, Finizola A, Homcy CJ, Vatner S. Mechanisms of supersensitivity to sympathomimetic amines in the chronically denervated heart of the conscious dog. Circ Res 1985;57:55-64.

17 Lurie KG, Bristow MR, Reitz B. Increased $\beta$-adrenergic receptor density in an experimental model of cardiac transplantation. $\mathcal{f}$ Thorac Cardiovasc Surg 1983;86: 195-201

18 Chester MR, Madden B, Barnett D, Yacoub $M$. The effect of orthotopic transplantation on total, $\beta_{1}$ - and $\beta_{2}$ adrenoceptors in the human heart. Br $¥$ Clin Pharmacol 1992;33:417-22.

19 Gilbert EM, Eiswirth CC, Mealey PC, Larrabee P, Herrick CM, Bristow M. $\beta$-Adrenergic supersensitivity Herrick CM, Bristow M. $\beta$-Adrenergic supersensitivity
of the transplanted human heart is presynaptic in origin. of the transplanted human

20 Bristow $M$. The surgically denervated, transplanted human heart. Circulation 1990;82:658-60.

21 Goldstein DS, Brush JE, Eisenhofer G, Stull R, Esler M In vivo measurement of neuronal uptake of norepinephrine in the human heart. Circulation 1988;78:41-8.

22 Wolfson S, Gorlin R. Cardiovascular pharmacology of propranolol in man. Circulation 1969;40:501-11.

23 Irving MH, Britton BJ, Wood WG, Padgham C, Carruthers $M$. Effects of beta adrenergic blockade on plasma catecholamines in exercise. Nature $1974 ; 248$ 531-3.

24 Christensen NJ, Galbo H, Hansen JF, Hesse B, Richter EA, Trap-Jensen J. Catecholamines and exercise. Diabetes 1979;28(suppl1):58-62.

25 Benedict CR, Pickering TG, Raine A. Acute and longterm effects of beta-adrenergic blockade on blood pressure and sympathetic activity in man. $\mathcal{F}$ Physiol 1977; 271:35P-36P.

26 Pope SE, Stinson EB, Daughters II GT, Ingels NB Alderman E. Exercise response of the denervated heart
in long-term cardiac transplant recipients. $A m \mathcal{F}$ Cardiol in long-term cardi

27 Donald DE, Shepherd J. Initial cardiovascular adjustmen to exercise in dogs with chronic cardiac denervation. $A m$ to exercise in dogs with chroni

28 Donald DE, Ferguson DA Milburn S. Effect of betaadrenergic receptor blockade on racing performance of 
greyhounds with normal and denervated hearts. Circ Res 1968;22:127-34.

29 Versteeg PGA Noble MIM, Stubbs J, Elzinga G. The effect of cardiac denervation and beta blockade on control of cardiac output in exercising dogs. Eur $\mathcal{F}$ Appl Physiol 1983;52:62-8.

30 Yusuf S, Theodoropoulos S, Dhalla N, et al. Influence of beta blockade on exercise capacity and heart rate response after human orthotopic and heterotopic cardiac transplantation. Am $\mathcal{F}$ Cardiol 1989;64:636-41.

31 Cryer P. Physiology and pathophysiology of the human sympathoadrenal neuroendocrine system. $N$ Engl $7 \mathrm{Med}$ 1980;303:436-44.

32 Goldstein D. Plasma norepinephrine as an indicator of sympathetic neural activity in clinical cardiology. $\mathrm{Am} \mathcal{F}$ Cardiol 1981;48:1147-54.

33 Francis GS, Godsmith SR, Ziesche SM, Cohn J. Response of plasma norepinephrine and epinephrine to dynamic exercise in patients with congestive heart failure. $A m \mathcal{F}$ Cardiol 1982;49:1152-6.

34 Levine TB, Olivari MT, Cohn J. Effects of orthotopic heart transplantation on sympathetic control mechaheart transplantation on sympathetic control mecha-
nisms in congestive heart failure. Am $f$ Cardiol 1986;58: nisms in $1035-40$.
35 Raine AEG, Erne P, Burgisser E, Muller FB, Bolli $P$, Buhler F. Atrial natiuretic peptide and atrial pressure in
patients with congestive heart failure. $N$ Engl $₹ \mathrm{Med}$ patients with cong

36 Forslund T, Fyhrquist F, Tikkanen I, et al. Plasma atria naturetic peptide in cardiac transplant recipients. A prospective study. Acta Med Scand 1988;224:3-7.

37 Singer DRJ, Buckley MG, Macgregor GA, Khagani A Banner NR, Yacoub $M$. Raised concentrations of plasma atrial naturetic peptides in cardiac transplant recipients. $B M F$ 1986;293:1391-2.

38 Singer DRJ, Banner NR, Cox A, et al. Response to dynamic exercise in cardiac transplant recipients: implications for control of the sodium regulatory hormone atrial natiuretic peptide. Clin Sci 1990;78:159-63.

39 Held P, Yusuf S, Mathias C, Dhalla N, Theodoropoulos $S$, Yacoub $M$. Renin response to sympathetic stimulation in cyclosporin-treated heart-transplant patients. $A m$ tion in cyclosporin-treated

40 Bellet M, Cabrol C, Sassano P, Leger P, Corvol P Menard J. Systemic hypertension after cardiac transplantation: effect of cyclosporine on the renin angiotensin-aldosterone system. Am $₹$ Cardiol 1985;56: angioten 